\title{
Experimental Testing of Basic Crash Elements Made of CFRP by Additive Tech- nologies
}

Tomáš Kalina, Stanislav Špirk, František Sedláček

Faculty of Mechanical Engineering, University of West Bohemia, 30614 Pilsen. Czech Republic. E-mail: tkalina@fst.zcu.cz,spirks@fst.zcu.cz, fsedlace@fst.zcu.cz

This paper deals with the experimental testing of the basic crash elements which are made of PA6 with short carbon fiber reinforcement by additive technology. Additive technologies allow the production of very complex, thin-walled and hollow shapes, which can be used to tune the desired characteristics of the deformation member. The variable size of the deceleration, the length of the deformed part and the total amount of energy absorbed can be controlled by suitable geometry. The initial impact peaks can be reduced by gradually changing the geometry. Experimental testing of the basic crash elements was performed on several specimens and average values are used in this paper. The maximal and the average deceleration and total energy absorbed are primarily monitored. The obtained data will be used for validation of material properties in Crash-Pam software. Usage of a validated material model, larger and more complex deformation members will be proposed, e.g. for the racing car Formula SAE.

Keywords: Crash element, Impact attenuator, Additive technologies, CFRP, Formula SAE

\section{Introduction}

All road vehicles, whether normal traffic or racing cars, place great emphasis on the safety of the crew [1]. One of the basic elements of vehicle passive safety is the Energy absorption element that is also called the Impact attenuator in Formula SAE. The basic frontal Impact attenuator is also designed and manufactured in Formula SAE (FSAE). Currently, most often FSAE uses impact attenuator made of hardened or metal foams, aramid or aluminium alloy honeycombs. These types of impact attenuators are used for their very good weight-to-energy ratio as well as for keeping the limits for average and maximum vehicle deceleration at the defined impact.

However, due to production technology (mainly honeycombs [2]) the possibilities of the impact attenuator shape is limited. We are able to produce complex shapes using additive technologies. Therefore, we could afford to optimize the shape of the impact attenuator for better deceleration characteristics and very low weight.

The energy absorption elements made by additive technologies are not commonly used in road vehicles yet. But there is a research that examines a metal crash-boxes with a printed filling from nylon [3].

The deformation elements are created by means of various metal crash-box elements [4], [5] and bumpers [5] made of shaped steel sheets in conventional road vehicles. Alternatively, they can be supplemented with various plastic or hardened or metal foams components [5]. However, conventional road vehicles are significantly heavier than the aforementioned FSAE vehicles and are also designed for collisions at higher speeds. Their deformation zones are therefore dimensioned for significantly greater energy absorption. The deformation elements made of composite parts [6] are used only in luxury or sports cars. Their main advantage is low weight, but their big disadvantage is a high price.

\section{Standard impact attenuators in Formula SAE}

The Impact attenuators are made in FSAE from various perforated sheets of steel or aluminum alloys [4], [5], hardened or metal foams [5], aluminum or composite honeycombs [2], etc. [7] The usage of each of these materials has its advantages and disadvantages. The sheet metal impact attenuators are generally heavier than those made of foam or honeycombs, which are generally standard today. Also the deformation members are made of composite laminates, which are very expensive and difficult to manufacture. The honeycombs, the foams and the laminates are usually glued [8] to impact the attenuator plate [9].

For example, the impact attenuators that have been tested for UWB vehicles (University of West Bohemia) and meet FSAE requirements that are: The aluminum alloy honeycomb impact attenuator of 200x200x100 mm weights $365 \mathrm{~g}$ and the aramid honeycomb impact attenuator of 200x200x100 mm with a relief holes weights $332 \mathrm{~g}$.

The rules [9] consider that IA assembly (impact attenuator (crash element), impact attenuator plate and 
fasteners) is mounted on the front of a vehicle with a total mass of $300 \mathrm{~kg}$ and impacting a solid, non-yielding impact barrier with a velocity of impact of $7 \mathrm{~m} / \mathrm{s}$. Impact attenuators appropriate to FSAE rules shall absorb a minimum deformation energy of $7350 \mathrm{~J}$ with a maximum deceleration not exceeding $40 \mathrm{~g}$ and an average deceleration not exceeding $20 \mathrm{~g}$. The minimum dimensions of the impact attenuators for FSAE are 200x200x100 mm but may not be fully filled. Holes can be formed in it [9].

\section{Basic crash elements - characteristics}

The aim of this article is to determine the basic mechanical properties of the material during the crash. PA6 with short carbon fiber reinforcement (PA6+SCF/CFRP) using the additive technology was chosen as the tested material. The geometry of the basic crash elements was also designed for testing, which is adapted to the available test equipment as well as the technological capabilities of the printer (3D printer Mark Two made by Markforged).

Basic dimensions of basic crash elemets are 90x90x90 mm. Basic crash elements are designed as Truncated cones' shells with anchoring base. The print settings are described in Tab. 1 and geometric properties of basic crash elements are specified by Tab. 2 and Fig. 1.

Tab. 1 Setting of the 3D printer Mark Two (Markforged)

\begin{tabular}{|l|l|}
\hline Width injection [mm] & 0.4 \\
\hline Height Layers [mm] & 0.1 \\
\hline Fill Pattern [-] & Triangular \\
\hline Fill Density [\%] & 28 \\
\hline Roof Layers [-] & 1 \\
\hline Floor Layers [-] & 1 \\
\hline Wall Layers [-] & 1 \\
\hline
\end{tabular}

Tab. 2 Properties of the basic crash elements

\begin{tabular}{|l|l|}
\hline Number Layers [-] & 900 \\
\hline Height [mm] & 90 \\
\hline Mass [g] & 35.2 \\
\hline Volume [mm^3] & 72793 \\
\hline Printing time [h] & 10.4 \\
\hline Material & ONYX (PA6+SCF) [10] \\
\hline
\end{tabular}

The paper [11], which was created in our department, deals with the determination of basic material parameters of PA6+SCF [11], [12]. This material is manufactured by Markforged company for the Mark Two printers with the trade name ONYX [10].

HPS (Horizontally Printed Specimens) from PA6 and PA6+SCF. These specimens were printed horizontally on the building platform. The angle between the main direction of the filaments and the testing direction was $0^{\circ}$. Average measured data for individual temperatures are given in Fig. 2 [11].

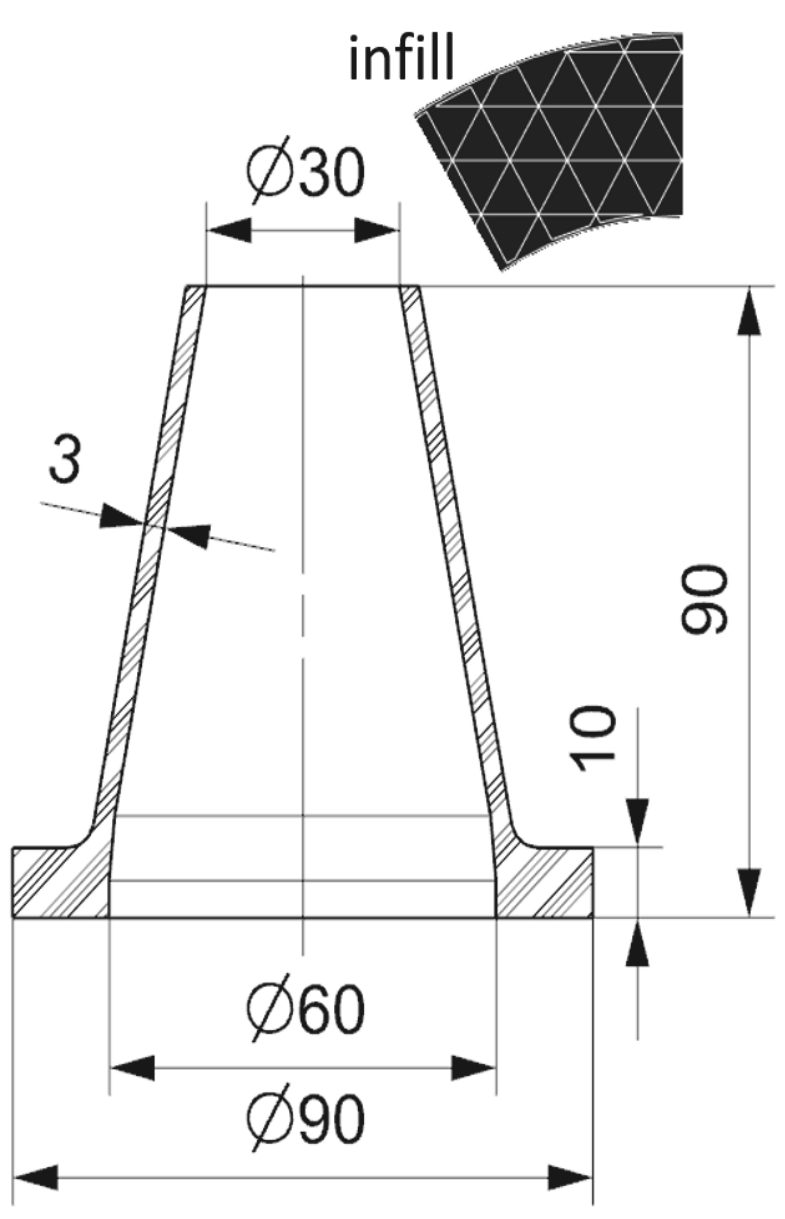

Fig. 1 Geometry of basic crash elements

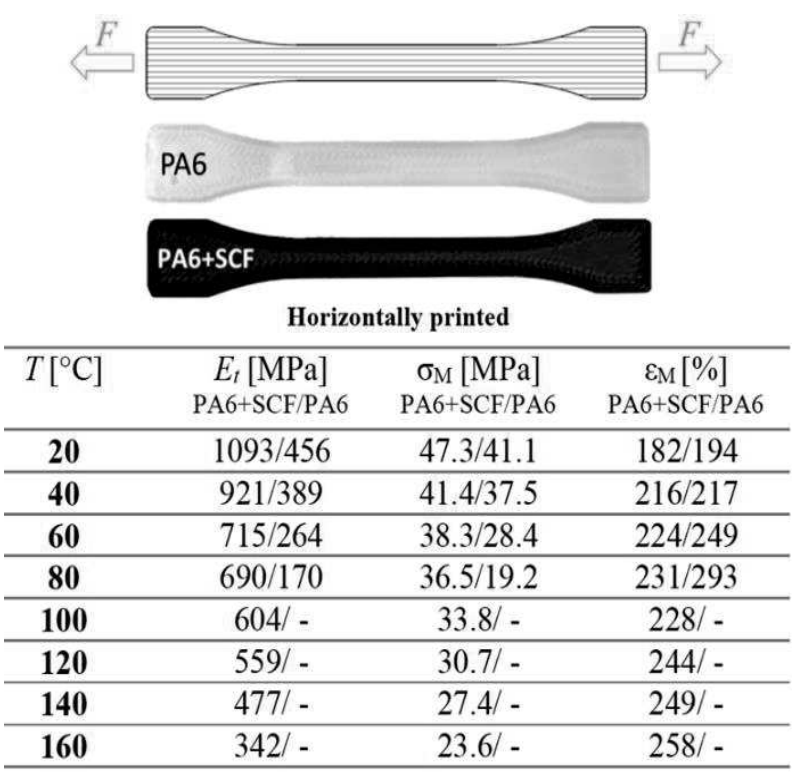

Fig. 2 Average experimental data of $\boldsymbol{H P S}$ from $P A 6+C F$ [11]

VPS (Vertically Printed Specimens) from PA6 and PA6+SCF. These specimens were printed vertically on the building platform. The angle between the main direction of the filament and the testing direction was $90^{\circ}$. The average measured data for individual temperatures are given in Fig. 3 [11]. 


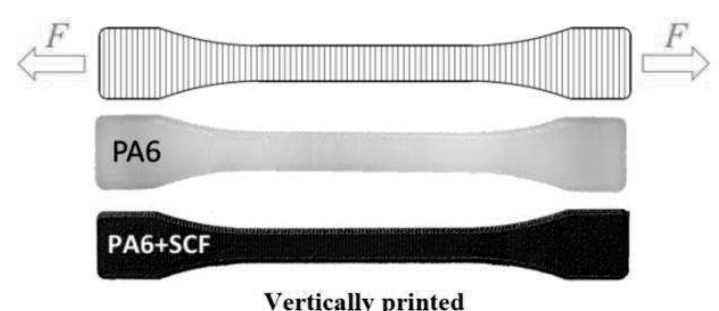

Vertically printed

\begin{tabular}{cccc}
\hline$T\left[{ }^{\circ} \mathrm{C}\right]$ & $\begin{array}{c}E_{t}[\mathrm{MPa}] \\
\text { PA6+SCF/PA6 }\end{array}$ & $\begin{array}{c}\sigma_{\mathrm{M}}[\mathrm{MPa}] \\
\text { PA6+SCF/PA6 }\end{array}$ & $\begin{array}{c}\varepsilon_{\mathrm{M}}[\%] \\
\text { PA6+SCF/PA6 }\end{array}$ \\
\hline $\mathbf{2 0}$ & $609 / 504$ & $28.9 / 27.1$ & $18.4 / 58.1$ \\
\hline $\mathbf{4 0}$ & $533 / 347$ & $25.1 / 13.2$ & $19.5 / 61.4$ \\
\hline $\mathbf{6 0}$ & $405 / 272$ & $21.6 / 11.9$ & $21.1 / 68.9$ \\
\hline $\mathbf{8 0}$ & $341 / 215$ & $19.1 / 10.2$ & $23.2 / 74.1$ \\
\hline $\mathbf{1 0 0}$ & $31 /-$ & $16.3 /-$ & $23.6 /-$ \\
\hline $\mathbf{1 2 0}$ & $294 /-$ & $14.9 /-$ & $24.4 /-$ \\
\hline $\mathbf{1 4 0}$ & $243 /-$ & $12.6 /-$ & $24.6 /-$ \\
\hline $\mathbf{1 6 0}$ & $202 /-$ & $10.1 /-$ & $24.9 /-$ \\
\hline
\end{tabular}

Fig. 3 The average experimental data of $\boldsymbol{V P S}$ from $P A 6+C F[11]$

\section{Experimental testing}

Tab. 3 The properties of experimental testing

\begin{tabular}{|l|l|}
\hline Number of specimens [-] & 4 \\
\hline Ram weight [kg] & 43.4 \\
\hline Fall height [mm] & 500 \\
\hline $\begin{array}{l}\text { Sampling frequency of the } \\
\text { accelerometer [Hz] }\end{array}$ & 38400 \\
\hline $\begin{array}{l}\text { Sampling period of the } \\
\text { accelerometer [ms] }\end{array}$ & 0.02604167 \\
\hline
\end{tabular}

Experimental testing was performed on the Falling weight impact testing machine. The ram's weight used was $43.4 \mathrm{~kg}$ and was dropped from the height of $500 \mathrm{~mm}$ above the sample. Ram deceleration was measured by accelerometer. The sampling frequency of the accelerometer was $38,400 \mathrm{~Hz}$, that sam- pling period was $0.02604167 \mathrm{~ms}$. The properties of experimental testing are summarized in Tab. 3.

\section{The results of experimental tests}

As already mentioned, 4 experimental tests of the same specimens were made. The average values were determined from the tests and are presented.

Fig. 4 shows test specimens from slow-motion camera during experiment a) before impact, b) impacted specimen No. 2 and c) impacted specimen No. 4. Samples b) and c) are shown in the state between the 1 st and the 2 nd impact. All measured data are displayed for the $1^{\text {st }}$ impact only. Secondary and other impacts caused by reflection by elastic deformation were cut off.
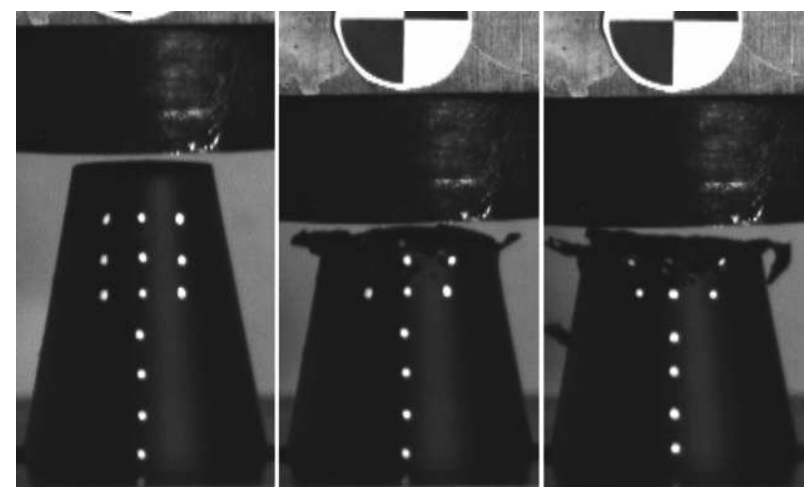

Fig. 4 Test specimens - a) before impact, b) and c) impacted specimens no. 2 and no. 4

Fig. 5 shows averaged measured values of 4 tests, simplified process and a linearized process of the middle section of deceleration-time diagram. In Tab. 4 shows the coordinates of simplified process curve. Individual points are connected by straight lines.

Tab. 5 summarizes the data determined from measurements and accelerometers.

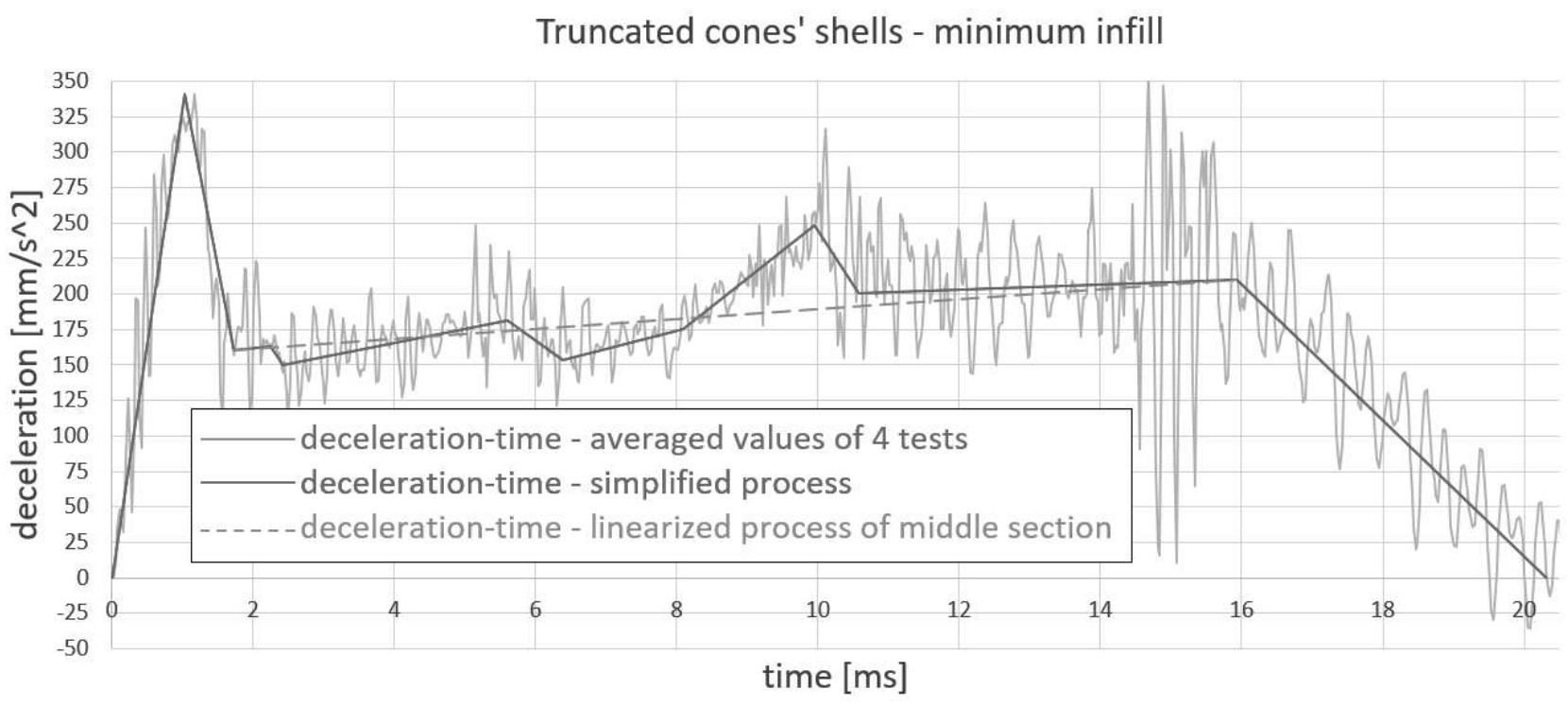

Fig. 5 Diagram deceleration-time 
Tab. 4The coordinates of simplified deceleration-time process

\begin{tabular}{|c|c|c|}
\hline $\begin{array}{c}\text { point } \\
\text { Nr. }\end{array}$ & time $[\mathrm{ms}]$ & deceleration $\left[\mathrm{mm} / \mathrm{s}^{\wedge} 2\right]$ \\
\hline 1 & 0.00 & 0.00 \\
\hline 2 & 1.02 & 340.71 \\
\hline 3 & 1.73 & 160.34 \\
\hline 4 & 2.25 & 163.27 \\
\hline 5 & 2.41 & 149.58 \\
\hline 6 & 5.61 & 181.36 \\
\hline 7 & 6.38 & 153.00 \\
\hline 8 & 8.09 & 175.00 \\
\hline 9 & 9.94 & 248.81 \\
\hline 10 & 10.57 & 200.42 \\
\hline 11 & 15.92 & 209.71 \\
\hline 12 & 20.32 & 0.00 \\
\hline
\end{tabular}

Tab. 5 The parameters determined from the experiment

\begin{tabular}{|l|l|}
\hline Deformed height $[\mathrm{mm}]$ & 21 \\
\hline Total deformation time $[\mathrm{ms}]$ & 20.3 \\
\hline Average deceleration $\left[\mathrm{mm} / \mathrm{s}^{\wedge} 2\right]$ & 174.9 \\
\hline Maximum deceleration $\left[\mathrm{mm} / \mathrm{s}^{\wedge} 2\right]$ & 340.8 \\
\hline
\end{tabular}

\section{The determination of deformation energy and velocity}

The equation (1) describes the potential energy of the weight that falls from the rest position at a height of $500 \mathrm{~mm}$ above the specimen. The same amount of energy must be absorbed by the specimen. Here applies (2), the kinetic energy of the impact is equal to the potential energy of the lifted weight above the specimen. The equation (3) describes as determined by the velocity of the weights before impact from kinetic energy.

$$
\begin{gathered}
E_{P}=m \cdot g \cdot h=43.3 \cdot 9,81 \cdot 0.5=212 \mathrm{~J} \\
E_{P}=E_{K}[\mathrm{~J}]
\end{gathered}
$$

Where:

$E_{P}$... Potential energy [],

$E_{K} \ldots$ Kinetic energy [J],

$m$... Mass [kg],

$g$... Gravitational acceleration $\left[\mathrm{m} / \mathrm{s}^{\wedge} 2\right]$,

b... Height $[\mathrm{m}]$,

$v \ldots$ Velocity $[\mathrm{m} / \mathrm{s}]$.

$$
E_{K}=0.5 \cdot m \cdot v^{2} \quad \rightarrow \quad v=\sqrt{\frac{E}{0,5 \cdot m}}=\sqrt{\frac{212}{0,5 \cdot 43.3}}=3.129 \frac{\mathrm{m}}{\mathrm{s}}
$$

The equation (4) describes the determination of the real FSAE impact attenuator, assuming a linear dependence of energy and weight and absorption of the required deformation energy of $7350 \mathrm{~J}$ [9]. It is not assumed that by increasing the deformation member of PA6 + SCF, energy and weight will increase linearly. It is only a rough calculation, whether it makes sense to solve the deformation member from PA6 + SCF.

$$
m_{P A-F S A E}=\frac{E_{P A-F S A E}}{E_{P A-S}} \cdot m_{P A-S}=\frac{7350}{212} \cdot 3.413=118 \mathrm{~g}
$$

Where:

$m_{P A-F S A E} \ldots$ Mass of the PA6+SCF deformation member complying with FSAE rules [g],

mPA-S ... Mass of the PA6+SCF deformed part of specimen $[\mathrm{g}]$,

$E_{P A-F S A E} \ldots$. Minimum required energy according to the FSAE rules [J],

$E_{P A}$-s ... Deformation energy absorbed by deformed part of specimen (Fig. 6 - orange part) []].

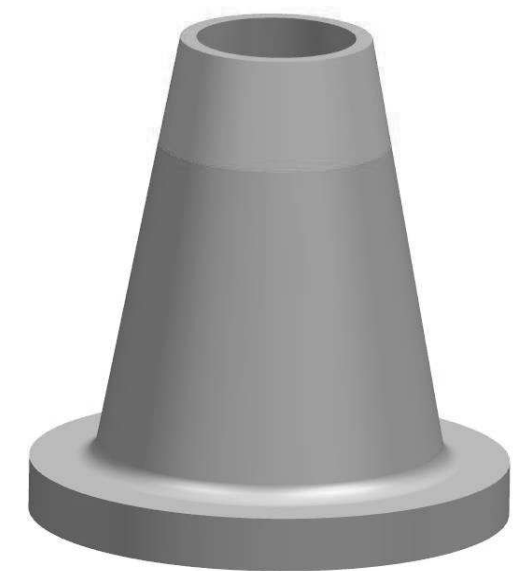

Fig. 6 Specimen with highlighted (orange) deformed part of specimen

\section{The discussion of results}

The height of the $21 \mathrm{~mm}$ specimen was deformed during the experiment. The deformed volume corresponds to approximately $3.413 \mathrm{~g}$ of material, while absorbing energy of $212 \mathrm{~J}$. Energy absorption of $7350 \mathrm{~J}$ is required according to FSAE requirements. The lowest weight of the proposed aramid honeycomb impact attenuator UWB is $332 \mathrm{~g}$. If we consider linear increase of energy with increasing volume, specifically weight, so with a larger impact attenuator or a plurality of basic crash elements, we would achieve a weight of approximately $118 \mathrm{~g}$ to absorb energy $7350 \mathrm{~J}$.

The diagram in Figure 5 can be divided into three basic parts. In the first part, which lasts less than $2 \mathrm{~ms}$, is the initial peak. During impact tests there is always an initial peak. The initial peak is caused by the initial resistance of the material on impact. A very high peak in connection with a deformation member can have negative effects on the crew, so there is an effort to reduce it. It is possible to adjust the size of the initial peak and its duration by using the appropriate geometry.

In the second part, the speed of the ram gradually slows down over a relatively long distance. This 
section lasts approximately $14 \mathrm{~ms}$. The slow deceleration on a longer distance is suitable for the safety of the car's crew. In this part, the majority of the kinetic energy of the ram is also absorbed. This part of the diagram is not linear as we can observe jumps within it. These jumps can be caused by averaging several partial results but they are also caused by uneven filling in the thin-walled cones. If we intersect a straight line through this whole section we get a slightly increasing line. This is due to the fact that the specimen is conical in shape and during the deformation there is a gradual increase in the cross-sectional area. In the third part, the ram stops completely within $4 \mathrm{~ms}$.

\section{Conclusion}

The experimental tests of basic crash elements were performed, which will be used for material validation in Crash-Pam software.

It was estimated that the resulting weight of the deformation member made of PA6+SCF (ONYX) could reach to $118 \mathrm{~g}$, based on the measured results and using direct proportionality. It is more than twice less weight than that of the aramid deformation member.

Obviously, the increase will not be linear and other criteria, such as maximum and average deceleration, are also placed on the impact attenuators. However, this suggests some potential that there is a possibility to design a PA6 + SCF deformation member that will have the desired properties and will have a lower weight and possibly a better shape to hide at the tip of the car.

The additive technology gives us the possibility of a very complicated, hollow and thin-walled shapes, therefore a sophisticated impact attenuator will be developed based on these experiments, which could achieve better properties than the existing deformation members.

\section{Acknowledgement}

This paper is based on work sponsored by project SGS-2019-030 (Research and development of Advanced Components for the Formula Student Car - University of West Bohemia).

\section{References}

[1] SPIRK, S. (2017) The collision of unbelted passenger with assessment of various vehicle interior. In: Manufacturing Technology, Vol.17, No.6, pp.962-969, UJEP, 2017, ISSN: 1213-2489.

[2] SAENZ-DOMINGUEZ, I., TENA, I., ESNAOLA, A., SARRIONANDIA, M., TORRE, J., AURREKOETXEA, J. (2019). Design and characterisation of cellular composite structures for automotive crash-boxes manufactured by out of die ultraviolet cured pultrusion. In: Composites Part B: Engineering, Vol.
160, pp. 217-224, doi.org/10.1016/j.compositesb.2018.10.046

[3] FU, X., ZHANG, X., HUANG, Z. (2020). Axial crushing of Nylon and $\mathrm{Al} /$ Nylon hybrid tubes by FDM 3D printing, In: Composite Structures, doi.org/10.1016/j.compstruct.2020.113055, IN PRESS, September 2020 Pre-proof

[4] SHI, D., XIAO, X. (2018). An enhanced continuum damage mechanics model for crash simulation of composites. In: Composite Structures, Vol. 185, pp. 774-785, doi.org/10.1016/j.compstruct.2017.10.084

[5] LI, Z., YU, Q., ZHAO, X., YU, M., SHI, P., YAND C. (2017) Crashworthiness and lightweight optimization to applied multiple materials and foam-filled front end structure of auto-body. In: Advances in Mechanical Engineering, Vol.9, No.8, pp.1-21, DOI: doi.org/10.1177/1687814017702806

[6] HUSSAIN, N. N., REGALLA, S. P., DASESWARA RAO, Y. V. (2017). Low velocity Impact Characterization of Glass Fiber Reinforced Plastics for Application of Crash Box. In: materialstoday, Vol. 4, No. 2, Part A, pp.3252-3262, doi.org/10.1016/j.matpr.2017.02.211

[7] RAZ, K., HORA, J., PAVLATA, P. (2017). Unconventional materials usage in design of vehicle bodies. In: Manufacturing Technology, Vol.17, No.5, pp.823-827, UJEP, 2017, ISSN: 12132489.

[8] KALINA, T.; SEDLACEK, F. (2019). Design and Determination of Strength of Adhesive Bonded Joints. In: Manufacturing Technology, Vol.19, No.3, pp.409-413, UJEP, 2019, ISSN: 1213-2489,

DOI: 10.21062/ujep/305.2019/a/1213$2489 / \mathrm{mt} / 19 / 3 / 409$

[9] Formula student FSG RULES 2020. Online. 5.1.2020. www.fsg.one/rules

[10] Material ONYX. Online. 5.1.2020. www.markforged.com/materials/onyx/

[11] SEDLACEK, F., LASOVA, V. (2018). Additive Manufacturing of PA6 with Short Carbon Fibre Reinforcement using Fused Deposition Modelling. Materials Science Forum (MSF), Vol.928, pp.26-31, ICCMME 2018, Singapore, ISSN 0255-5476.

[12] RAZ, K., ZAHALKA, M., CHVAL, Z., KUCEROVA, L. (2017). Analysis of Weld Line Influence on Strength of Nylon Parts. In: $M a-$ nufacturing Technology, Vol.17, No.4, pp.561-565, UJEP, 2017, ISSN: 1213-2489 